\title{
PREFACE
}

\section{Introduction: Advances in Palaeogeography}

\author{
G. MEINHOLD*\$ \\ *School of Geography, Geology and the Environment, Keele University, Keele, Staffordshire, \\ ST5 5BG, UK
}

\$Author for correspondence: g.meinhold@keele.ac.uk

This special issue of Geological Magazine is dedicated to the memory of Dr Alan Gilbert Smith, Fellow of St John's College and Emeritus Reader in Geology at the University of Cambridge, who passed away on 13 August 2017 at the age of 80 years. I first met Alan on the 5th International Symposium on Eastern Mediterranean Geology in Thessaloniki, Greece, in spring 2004 and later during several occasions when I was working on the Cambridge Arctic Shelf Programme (CASP) in Cambridge. The palaeotectonic evolution of Greece was one of our common interests. Alan was one of the pathfinders in palaeogeographic research in the 20th century. Together with Sir Edward Bullard (1907-1980) and Jim E. Everett, he published the first computational approach in palaeogeography in their famous paper 'The fit of the continents around the Atlantic' (Bullard, Everett \& Smith 1965), which shows a very accurate geometrical fit of the circum-Atlantic continents using the early Cambridge University EDSAC 2 computer. Later, in a contribution in Nature entitled 'The fit of the southern continents', Smith \& Hallam (1970) presented the first computer fit of the contour of the southern continents forming Gondwanaland. Worth mentioning are also his detailed palaeogeographical maps of the entire Earth, down to epoch level (e.g. Smith, Briden \& Drewry 1973; Smith, Hurley \& Briden 1981) and his work on the first three editions of 'A Geologic Time Scale' (Harland et al. 1982, 1990; Gradstein, Ogg \& Smith 2005). Alan's great achievements in the Earth sciences have stimulated new ideas and had a huge impact on geological research, including palaeogeography.

Palaeogeography addresses the cartographic reconstruction of former geographical features on palinspastically restored tectonic base maps either for a specific region or the entire globe in time slices through Earth's geological history. The topography of land masses, the bathymetry of former seas and the circulation of oceanic waters, former wind patterns and 
distribution of organisms, among others, are also often included in such reconstructions. Major palaeogeographical reorganization of geographical features strongly influences mountain formation, basin development, as well as the evolution of ecosystems and the climate. Understanding current climatic changes on Earth, such as global warming and the rates involved is only possible if we know their history back through geological time.

The special issues, Advances in Palaeogeography, aims to present a well-balanced selection of the current state of palaeogeography-related research of which the concept of plate tectonics is an integral part. Before recognising that something has advanced one needs to know the present state of knowledge about the past. It is therefore mandatory to give also some credit to the pioneers in the field of palaeogeography and related studies, that is the individuals who came up with innovative yet often provocative ideas which finally led to the establishment of the theories of continental drift and plate tectonics.

This special issue of Geological Magazine presents a collection of ten papers which address a wide range of topics related to palaeogeography. These papers are grouped under four categories: (1) historical considerations on palaeogeography, continental drift, and plate tectonics, (2) methods and techniques used for palaeogeographic and plate tectonic reconstructions, including a presentation of a selection of time slices, (3) highlighting the importance of palaeogeography for Earth's climatic evolution, and (4) presenting examples of the use of palaeogeographic knowledge for the exploration of natural resources.

\section{Historical considerations}

Meinhold \& Şengör provide a historical review of how continental drift and plate tectonics supplied the framework for our current understanding of palaeogeography. Special emphasis is given to innovative ideas and scientific milestones since the dawn of 'palaeogeography' in the 16th century onwards for the development of the theory of continental drift, superseded by the theory of plate tectonics, which finally led to the establishment of the modern phase of palaeogeography as a recognized discipline of the Earth sciences.

\section{Methods, techniques, and time slices}

In the mid-1960s, the plate tectonics theory kicked off and revolutionized thinking about the mobility of Earth's lithosphere. Already by the early 1970s, the term 'plate tectonics' was well established and plate tectonic models flourished among the Earth sciences community. 
Verard reviews and validates the different types of plate tectonic models and discusses perspectives for the generation of global tectonic models in the future.

Performing plate tectonic reconstructions requires a thorough understanding of a wide range of processes that affect the Earth's lithosphere. The integration of various sets of data is essential as outlined by Torsvik \& Cocks. In their study, they exemplarily demonstrate how palaeomagnetism, mantle tomography, and the geological record including the analysis of fossils and identification of faunal and floral provinces, besides the rock record itself (e.g. facies and glacial features), allow the location of ancient continents to be deciphered back in time. The application of the novel plume generation zone method is explored. A selection of reconstructions for various time slices throughout the Phanerozoic is presented.

Lineated magnetic anomalies recorded in oceanic rocks generated by sea-floor spreading and fracture zones allow the precise reconstruction of past plate motions. Because of the virtual absence of in situ oceanic crust of pre-Jurassic age this approach is not possible for palaeogeographic reconstructions older than $\sim 200$ Ma. Domeier \& Torsvik tackle this problem and present a workflow for making full-plate models for pre-Jurassic time.

One of the key techniques nowadays routinely used for unravelling the age of igneous and metamorphic rocks and for deciphering the origin of siliciclastic sediments and sedimentary rocks is $\mathrm{U}-\mathrm{Pb}$ geochronology. Such data are essential to palaeogeographic reconstructions. Stephan et al. compiled a large dataset of detrital zircon $\mathrm{U}-\mathrm{Pb}$ ages from Precambrian and Lower Palaeozoic sedimentary rocks and applied a statistical provenance analysis for the Peri-Gondwana crust north of Africa and adjacent areas to test the published tectonic models for the pre-Variscan time. Their study reveals a vast and contiguous PeriGondwana shelf south of the Rheic Ocean with sediment supply from two contrasting zircon provinces.

Earth's vertical surface motion is largely a consequence of mantle convection. Vertical surface motion can expose rocks which are then likely subject of erosion leaving gaps in the geological record represented by unconformities on geological maps. Friedrich introduces a new method to visualize the time gaps in the geological record and discusses their use as a proxy for the relative intensity of Earth's vertical surface motion. By calibrating hiatus areas and their changes over time using independent geological data such as obtained, for example, from low-temperature thermochronology, the new hiatus mapping method can be used to improve palaeotopographic reconstructions which may be compared against mantle convection models. 
Advances in palaeogeographic reconstructions can be made by integrating and then coupling various global models as outlined by Verard. This approach is used for the PANALESIS model which couples a global plate tectonic model with a topographic model, a climate model and a vegetation model and leads to synthetic global palaeogeographies at any reconstructed time slice.

\section{Palaeogeography and climate}

Since the 1910s, when Alfred Wegner presented his revolutionary theory of continental drift, one of the most prominent and well-known tools for palaeogeographic reconstructions has been the use of climate-sensitive lithologies such as coals, evaporites and glacial deposits. However, this approach works only if the climate-sensitive lithologies show a stable latitudinal distribution through greenhouse and icehouse regimes. Cao et al. investigate this premise in detail back to the Devonian period. They test the sensitivity of the latitudinal distribution of climate-sensitive lithologies to variations of land-sea surface areas and to global tectonic models including the use of statistical methods. Their study shows that the palaeolatitudinal distributions of climate-sensitive lithologies have changed through geological time. This has implications for the reliability of palaeogeographic reconstructions using climate-sensitive lithologies and hence needs to be considered in future studies.

Throughout Earth history the level of atmospheric $\mathrm{CO}_{2}$ concentration has changed. The reasons for that are manifold. Goddéris \& Donnadieu explore the role of palaeogeography in the changes in atmospheric $\mathrm{CO}_{2}$ concentrations for the Phanerozoic using the numerical model GEOCLIM. They show that the interplay between palaeogeographic configuration and magmatic degassing rate is the main driver of the atmospheric $\mathrm{CO}_{2}$ evolution from the beginning of the Palaeozoic Era to the Cenozoic Era, with the exception of the Late Palaeozoic ice age where other parameters seem to have played a prominent role.

\section{Economic importance}

Changes in palaeogeographic configuration also influence the formation and distribution of natural resources such as mineral deposits and oil and gas. Studying palaeogeography is therefore essential for the exploration of natural resources to meet the world's needs in the future. Markwick provides a thorough review including three case studies (global Maastrichtian, Cameroon-Gabon, and central Pyrenees) to show how palaeogeography is 
used within the exploration workflow to help mitigate the geological risks in hydrocarbon exploration. A comprehensive workflow for building palaeogeographies is described to provide a standard approach that can be applied for a range of tasks in exploration and Academia to better understand the Earth system.

Acknowledgements. I am grateful to all contributors to this issue and the referees who helped with timely reviews. I warmly thank Mark Allen (former Editor-in-Chief, Geological Magazine) for providing me with an opportunity to initiate this special issue, and Peter Clift (Editor-in-Chief, Geological Magazine) for continued support for successfully accomplishing it. I also wish to thank Susie Bloor (Editorial Office, Geological Magazine), Kathleen Too (Publishing Editor, Cambridge University Press) for their timely help with communications and production.

\section{References}

Bullard, E., Everett, J. E. \& Smith A. G. 1965. The fit of the continents around the Atlantic. Philosophical Transactions of the Royal Society of London, Series A, Mathematical and Physical Sciences 258, 41-51.

Gradstein, F., OgG, J. \& Smith, A. G. (eds) 2005. A Geologic Time Scale 2004. Cambridge: Cambridge University Press, 610 pp.

Harland, W. B., Cox, A. V., Llewellyn, P. G., Pickton, C. A. G., Smith, A. G. \& Walters, R. 1982. A Geologic Time Scale. Cambridge: Cambridge University Press, $131 \mathrm{pp}$.

Harland, W. B., Armstrong, R. L., Cox, A. V., Craig, L. E., Smith, A. G. \& Smith, D. G. 1990. A Geologic Time Scale 1989. Cambridge: Cambridge University Press, 263 pp.

Smith, A. G. \& Hallam, A. 1970. The fit of the southern continents. Nature 225, 139-44.

Smith, A. G., Briden, J. C. \& Drewry, G. E. 1973. Phanerozoic world maps. In Organisms and Continents Through Time (ed. N. F. HugHES), pp. 1-42. Special Papers in Palaeontology no. 12.

Smith, A. G., Hurley, A. M. \& Briden, J. C. 1981. Phanerozoic palaeocontinental world maps. Cambridge: Cambridge University Press, 102 pp. 